\title{
Point source sulphur dioxide peaks and hospital presentations for asthma
}

\author{
A Michael Donoghue, Mervyn Thomas
}

\begin{abstract}
Objective-To examine the effect on hospital presentations for asthma of brief exposures to sulphur dioxide $\left(\mathrm{SO}_{2}\right)$ (within the range $0-8700 \mu \mathrm{g} / \mathrm{m}^{3}$ ) emanating from two point sources in a remote rural city of 25000 people.

Methods-A time series analysis of $\mathrm{SO}_{2}$ concentrations and hospital presentations for asthma was undertaken at Mount Isa where $\mathrm{SO}_{2}$ is released into the atmosphere by a copper smelter and a lead smelter. The study examined 5 minute block mean $\mathrm{SO}_{2}$ concentrations and daily hospital presentations for asthma, wheeze, or shortness of breath. Generalised linear models and generalised additive models based on a Poisson distribution were applied.

Results-There was no evidence of any positive relation between peak $\mathrm{SO}_{2}$ concentrations and hospital presentations or admissions for asthma, wheeze, or shortness of breath.

Conclusion-Brief exposures to high concentrations of $\mathrm{SO}_{2}$ emanating from point sources at Mount Isa do not cause sufficiently serious symptoms in asthmatic people to require presentation to hospital. (Occup Environ Med 1999;56:232-236)
\end{abstract}

Keywords: $\mathrm{SO}_{2}$; short term exposure; asthma

Short term exposures to high concentrations of $\mathrm{SO}_{2}$ within experimental chambers are known to provoke bronchoconstriction in normal subjects. $^{12}$ The same response occurs in asthmatic people at lower concentrations especially if they are exercising at the time. ${ }^{2-6}$ The response is typically maximal within 5 minutes and resolves spontaneously after 30-60 minutes. ${ }^{157}$ It is prevented and relieved by inhaled $\beta_{2}$ agonists. $^{7-9}$ Although individual exposure-response characteristics have been well defined under experimental conditions, the effect on populations of brief exposures to high concentrations of $\mathrm{SO}_{2}$ emanating from point sources has not been examined. This study is a time series analysis of 5 minute block mean $\mathrm{SO}_{2}$ concentrations and hospital presentations for asthma, wheeze, or shortness of breath in the city of Mount Isa, where $\mathrm{SO}_{2}$ is released into the atmosphere by a copper smelter and a lead smelter. Mount Isa is a remote rural city in north west Queensland with a population of about 25000 people. The smelter emissions are dispersed away from the city by two tall stacks, and an air quality control system is used to minimise ground level expo- sures of $\mathrm{SO}_{2}$ during adverse meteorological conditions. Continuous data from $10 \mathrm{SO}_{2}$ monitors located on two concentric rings within the city, and meteorological forecasts are used to detect and predict rising exposures. The copper smelter, which produces most of the $\mathrm{SO}_{2}$, is shut down if the short term limits set by the United States Environmental Protection Agency are likely to be approached (3 hour running average of $1300 \mu \mathrm{g} / \mathrm{m}^{3}$ and 24 hour running average of $365 \mu \mathrm{g} / \mathrm{m}^{3}$ ). The resultant exposure to $\mathrm{SO}_{2}$ in the city is characterised by a very low background concentration (mean annual concentration of $<20 \mu \mathrm{g} / \mathrm{m}^{3}$ ) with occasional peaks of up to $8700 \mu \mathrm{g} / \mathrm{m}^{3}$. Observations of the continuous chart recordings show that these peaks rarely persist longer than 5 minutes. During the 3 year study period, the peak $\mathrm{SO}_{2}$ concentration recorded anywhere in the city did not exceed $800 \mu \mathrm{g} / \mathrm{m}^{3}$ on $48.3 \%$ of days. This concentration has been reported as the lowest required to double airway resistance in the most sensitive of male asthmatic subjects exercising during experimental chamber studies.

\section{Method}

The 3 year period from 1 July 1993 to 30 June 1996 was studied.

\section{EXPOSURE DATA}

For each day of the years studied, the maximum 5 minute block mean concentration of $\mathrm{SO}_{2}$ recorded by any of the 10 monitors was determined. Computer recorded 5 minute block averages were available for 1070 days $(97.6 \%)$. Visual inspection of the original chart recordings yielded peak value data for the missing days.

\section{RESPONSE DATA}

Deidentified data were requested from Mount Isa Base Hospital on presentations for asthma. For each day of the years studied, the number of people presenting to the emergency department complaining of asthma, wheeze, or shortness of breath was determined from the attendance records. The number of these people who were then admitted to hospital was also determined. All of these patients were included in the study, regardless of age, sex, ethnicity, smoking status, or place of usual residence. Response data were obtained for every day studied.

STATISTICAL ANALYSIS

Descriptive statistics for numbers of patients presenting, and numbers admitted were calculated, in aggregate and for each month. 
Table 1 Mean and variance of daily presentations at Mount Isa Base Hospital by month of the year (data for each month are aggregated over all 3 years of the study)

\begin{tabular}{llllll}
\hline & \multicolumn{2}{l}{ Presentations } & & \multicolumn{2}{l}{ Admissions } \\
\cline { 2 - 3 } \cline { 5 - 6 } Month & Mean & Variance & & Mean & Variance \\
\hline Jan & 1.172 & 1.144 & & 0.312 & 0.347 \\
Feb & 1.494 & 1.991 & & 0.388 & 0.359 \\
Mar & 1.591 & 1.309 & & 0.462 & 0.338 \\
Apr & 1.289 & 1.331 & & 0.311 & 0.329 \\
May & 1.667 & 1.812 & & 0.366 & 0.517 \\
Jun & 1.567 & 1.597 & & 0.489 & 0.567 \\
Jul & 1.677 & 2.199 & & 0.366 & 0.278 \\
Aug & 2.043 & 2.563 & & 0.462 & 0.490 \\
Sep & 1.633 & 2.055 & & 0.356 & 0.411 \\
Oct & 1.226 & 1.481 & & 0.247 & 0.253 \\
Nov & 1.000 & 1.483 & & 0.189 & 0.200 \\
Dec & 1.151 & 1.586 & & 0.226 & 0.177 \\
\hline
\end{tabular}

Histograms were drawn, and compared with a Poisson distribution of the same mean.

A frequency distribution was generated of the number of days for each month of the year on which the maximum 5 minute block average $\mathrm{SO}_{2}$ concentration exceeded three levels $(>800$ $\left.\mu \mathrm{g} / \mathrm{m}^{3},>2145 \mu \mathrm{g} / \mathrm{m}^{3},>5434 \mu \mathrm{g} / \mathrm{m}^{3}\right)$.

The effect of $\mathrm{SO}_{2}$ concentration and seasonality were investigated with generalised linear models (GLMs).$^{10}$ A Poisson error distribution was used, with a log link function. The Poisson assumption was checked through examination of deviance residuals. ${ }^{10}$ In this context, GLMs may be thought of as a generalisation of linear regression and the analysis of covariance, to cope with data that are not normally distributed.

The GLM included a covariate for $\mathrm{SO}_{2}$ concentration and a 12 level factor for month. Sulphur dioxide by month interactions were also fitted. As the concentration of $\mathrm{SO}_{2}$ is itself seasonal, two forms of analysis were conducted. In the first form of analysis $\mathrm{SO}_{2}$ concentration was fitted before month. In the second analysis the $\mathrm{SO}_{2}$ effect was fitted after month. There was no evidence of extra-Poisson variability, and variances were therefore not inflated by a heterogeneity factor.

Informally the first analysis considered the issue of whether there was any relation between $\mathrm{SO}_{2}$ and asthma presentations or admissionseven if it is due to a shared seasonality. The second analysis considered the question of whether or not there was a relation between asthma presentations or admissions and $\mathrm{SO}_{2}$ over and above the fact that both change seasonally.

Table 2 A frequency distribution ( $n(\%))$ of days for each month of the year on which the maximum 5 minute block average sulphur dioxide concentration exceeded the stated concentrations (data for each month are aggregated over all 3 years of the study)

\begin{tabular}{llll}
\hline Month & $>800 \mu \mathrm{g} / \mathrm{m}^{3}$ & $>2145 \mu \mathrm{g} / \mathrm{m}^{3}$ & $>5434 \mu \mathrm{g} / \mathrm{m}^{3}$ \\
\hline Jan & $74(79.6)$ & $58(62.4)$ & $33(35.5)$ \\
Feb & $46(54.1)$ & $39(45.9)$ & $13(15.3)$ \\
Mar & $31(33.3)$ & $18(19.4)$ & $5(5.4)$ \\
Apr & $27(30.0)$ & $12(13.3)$ & $6(6.6)$ \\
May & $25(26.9)$ & $15(16.1)$ & $2(2.2)$ \\
Jun & $36(40.0)$ & $26(28.9)$ & $7(7.8)$ \\
Jul & $42(45.2)$ & $32(34.4)$ & $15(16.1)$ \\
Aug & $22(23.7)$ & $16(17.2)$ & $6(6.5)$ \\
Sep & $58(64.4)$ & $52(57.8)$ & $17(18.9)$ \\
Oct & $64(68.8)$ & $58(62.4)$ & $21(22.6)$ \\
Nov & $71(78.9)$ & $64(71.1)$ & $21(23.3)$ \\
Dec & $72(77.4)$ & $64(68.8)$ & $29(31.2)$ \\
\hline
\end{tabular}

The possibility of a non-linear dependence of asthma presentations or admissions on $\mathrm{SO}_{2}$ was investigated with generalised additive models (GAMs). ${ }^{11}$ These methods may be thought of as a further generalisation of GLMs. As well as accommodating non-normal error distributions, GAMs may be used to include non-linear and non-parametric relations. The dependent variable is constrained to vary smoothly with the predictor variables, but the precise form of the dependence is chosen by the data. In our analyses the effect of $\mathrm{SO}_{2}$ concentration was modelled by a smoothing spline with about four degrees of freedom.

Graphical diagnostics were used to check the assumptions of the GLMs and GAMs. Deviance residuals ${ }^{12}$ were calculated and plotted against predicted values. Kernel density estimates and histograms of the residuals were generated.

All analyses were based on the assumption that responses in successive days were statistically independent (conditional on $\mathrm{SO}_{2}$ concentrations). Dependence between successive days is likely to inflate the variance of parameter estimates, leading our analysis to overestimate the evidence of any $\mathrm{SO}_{2}$ exposure effect on asthma. The independence assumption was checked informally, using time series analysis of deviance residuals.

The S Plus software package was used for all statistical analyses.

\section{Results}

DESCRIPTIVE STATISTICS

Table 1 shows the mean and variance of daily presentations and daily admissions by month. The variance for each month was nearly equal to the mean-which is consistent with a Poisson distribution for each month.

Table 2 is a frequency distribution showing the number (\%) of days for each month of the year on which the maximum 5 minute block average $\mathrm{SO}_{2}$ concentration exceeded three levels $\left(>800 \mu \mathrm{g} / \mathrm{m}^{3},>2145 \mu \mathrm{g} / \mathrm{m}^{3},>5434 \mu \mathrm{g} / \mathrm{m}^{3}\right)$. Data for each month are aggregated over all 3 years of the study. The three $\mathrm{SO}_{2}$ concentrations correspond to the minimum, median, and maximum concentrations required in experimental chamber studies to cause a doubling of airway resistance in male asthmatic subjects during moderate exercise. ${ }^{4}$

\section{ANALYSIS FOR PRESENTATIONS}

Poisson regression

The analysis of deviance for the GLM is shown in table 3. The test for a relation with $\mathrm{SO}_{2}$ in the absence of a month effect had a $\chi^{2}$ statistic of 19.86 on 1 degree of freedom and an infinitesimal $\mathrm{p}$ value-indicating strong evidence for a

Table 3 Analysis of deviance for GLM fitted to asthma presentations at Mount Isa Base Hospital (the p value represents the tail area probability of a $\chi^{2}$ variate equal to the deviance, with the given number of degrees of freedom)

\begin{tabular}{lrcc}
\hline Effect & Df & Deviance & p Value \\
\hline Month & 11 & 60.821 & 0.000 \\
$\mathrm{SO}_{2}$ ignoring month & 1 & 19.861 & 0.000 \\
$\mathrm{SO}_{2}$ allowing for month & 1 & 4.461 & 0.035 \\
$\mathrm{Month} \mathrm{SO}_{2}$ interaction & 11 & 12.535 & 0.325 \\
\hline
\end{tabular}




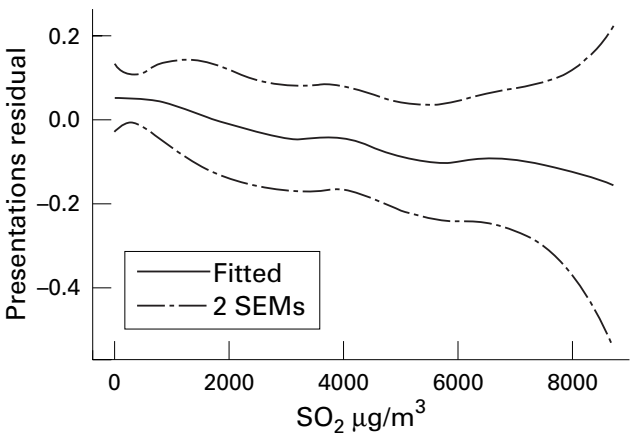

Figure 1 Generalised additive model fit of presentations to $\mathrm{SO}_{2}$ concentrations. The generalised additive model includes a smoothing spline response for $\mathrm{SO}_{2}$ and a term representing the effect of month. The solid line shows a smoothing spline fit to the partial residual, and the broken lines represent plus or minus 2 SE. There is no strong evidence for any relation, and the data are not consistent with a positive trend in presentations with $\mathrm{SO}_{2}$ concentrations.

relation between $\mathrm{SO}_{2}$ and presentations. The regression coefficient, however, was negativeindicating that high $\mathrm{SO}_{2}$ values were associated with lower numbers of people presenting with asthmatic symptoms. There is clear evidence of a month effect, and the apparent relation between $\mathrm{SO}_{2}$ and presentations is almost certainly due to a shared seasonality. When month was fitted, the addition of $\mathrm{SO}_{2}$ to the model was just significant. The parameter estimate for $\mathrm{SO}_{2}$ in the presence of a month effect, however, was $-2.42 \times 10^{-5}$ (SE $1.115 \times$ $\left.10^{-5}\right)$. This indicated a negative relation between $\mathrm{SO}_{2}$ concentrations and presentations. Clearly fitting month as a factor has not entirely removed the effect of shared seasonality.

The month by $\mathrm{SO}_{2}$ interaction was not significant, and there was no evidence that the slope of the relation between $\mathrm{SO}_{2}$ and presentations changes with month.

This analysis provided no evidence of any tendency for peak $\mathrm{SO}_{2}$ concentrations to be associated with higher incidence of presentations.

Non-linear response to $\mathrm{SO}_{2}$

The GAM model (including a smoothing spline to fit $\mathrm{SO}_{2}$ ) was compared with a GLM model (including a linear relation between $\mathrm{SO}_{2}$ and presentations) with an approximate likelihood ratio $\chi^{2}$ test. The month effect was included in both models. The value of $\chi^{2}$ was 1.6 on 3 degrees of freedom; the $p$ value was 0.639 . The departure from linearity was not significant-indicating that the GLM analysis was satisfactory. A partial residual plot for the $\mathrm{SO}_{2}$ term in the GAM is shown in figure 1 . This plot indicates a weak negative linear relation between $\mathrm{SO}_{2}$ and presentations.

Table 4 Analysis of deviance for GLM fitted to asthma admissions at Mount Isa Base Hospital (the p value represents the tail area probability of a $\chi^{2}$ variate equal to the deviance, with the given number of degrees of freedom)

\begin{tabular}{llll}
\hline Effect & Df & Deviance & p Value \\
\hline Month & 11 & 27.61 & 0.004 \\
$\mathrm{SO}_{2}$ ignoring month & 1 & 7.72 & 0.005 \\
$\mathrm{SO}_{2}$ allowing for month & 1 & 1.28 & 0.257 \\
${\mathrm{Month} \mathrm{by} \mathrm{SO}_{2} \text { interaction }}^{11}$ & 9.18 & 0.605 \\
\hline
\end{tabular}

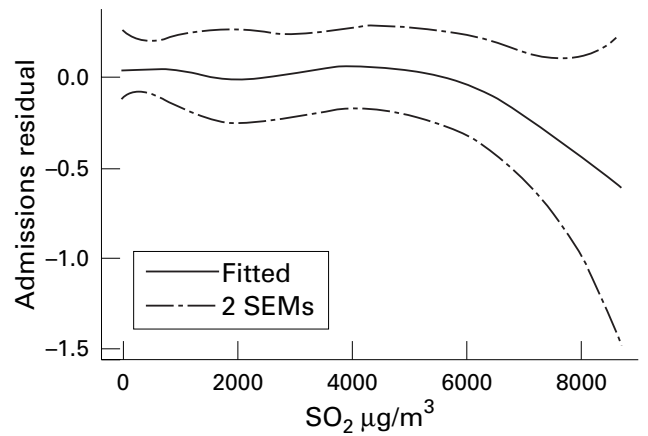

Figure 2 Generalised additive model fit of admissions to $\mathrm{SO}_{2}$ concentrations. The generalised additive model includes a smoothing spline response for $\mathrm{SO}_{2}$ and a term representing the effect of month. The solid line shows a smoothing spline fit to the partial residual, and the broken lines represent plus or minus 2 SE. There is no strong evidence for any relation, and the data are not consistent with a positive trend in admissions with $\mathrm{SO}_{2}$ concentrations.

\section{Model diagnostics}

Analysis of the variance residuals and predicted values suggest the GLM is appropriate.

\section{ANALYSIS FOR ADMISSIONS}

Poisson regression

The analysis of deviance for the GLM is shown in table 4 . When the effect of $\mathrm{SO}_{2}$ was considered in the absence of a month effect, the $\chi^{2}$ statistic was 7.72 on 1 degree of freedom, indicating a strong relation between admissions and $\mathrm{SO}_{2}$. The regression coefficient, however, was negative-indicating that high $\mathrm{SO}_{2}$ concentrations were associated with a lower incidence of admissions related to asthma. This was again an artefact caused by a shared seasonality in $\mathrm{SO}_{2}$ and asthma admissions. There is clear evidence of a month effect. When month was included in the model there was no further evidence for an effect of $\mathrm{SO}_{2}$ concentrations. Neither was there any evidence that the slope of the relation between $\mathrm{SO}_{2}$ and admissions changes with month.

Non-linear response to $\mathrm{SO}_{2}$

The $\chi^{2}$ test statistic for the hypothesis of no departures from linearity was 2.558 on 3 degrees of freedom with a $\mathrm{p}$ value of 0.465 . There was no evidence of any departure from linearity.

The partial residual plot for the smoothing spline in $\mathrm{SO}_{2}$ is shown in figure 2. There is no evidence of any relation between admissions and $\mathrm{SO}_{2}$, either linear or non-linear.

\section{Model diagnostics}

Analysis of the variance residuals and predicted values suggested the GLM was appropriate.

\section{Discussion}

This study adopted an analytical framework based on Poisson distributed responses, which adequately reflected the distributional properties of small daily counts. Seasonal effects were examined with the models described, and a clear relation between asthma and month was established, with the winter months showing more presentations, and more admissions. A slight negative relation between presentations, 
and peak $\mathrm{SO}_{2}$ concentrations was found and was an artefact of a shared seasonality - which has not been completely accounted for by fitting month. No relation between admissions and peak $\mathrm{SO}_{2}$ concentrations was found. Although the assumption of conditional independence of successive days might be challenged, the likely impact of error in this assumption would be to inflate the evidence for a relation between $\mathrm{SO}_{2}$ and asthma presentations or admissions. As the study has shown no evidence of such a relation, our assumption was innocuous. In particular, there was no reason to consider more complex models that were based on correlations between successive days.

The exposure data consisted of the highest daily computer recorded 5 minute block mean from all 10 monitors. The reason we selected the 5 minute sample period was that we were specifically looking for responses to brief peaks. Experimental chamber studies indicate that exposure concentration is the most important determinant of responses, and only a brief sample period would detect the highest concentrations that occurred. In the spatial analysis, the spatial density of monitoring stations at Mount Isa was much higher than in any previous study that we are aware of. It is likely that the monitors would detect most of the peaks occurring anywhere in this small city. Conducting subanalyses at each of the locations could be done, but would greatly increase the complexity of the study. All 10 monitors are located within the city, so they would not have registered $\mathrm{SO}_{2}$ concentrations in unoccupied areas. Exposure data were obtained for every day of the study period for all 10 monitors.

Other pollutants such as particulates, ozone, and oxides of nitrogen were not studied. If they modified the effect of $\mathrm{SO}_{2}$, however, they must have been protective, given that the study outcome was negative. We are not aware of any evidence that these other pollutants reduce exacerbation or severity of asthma. We do not, therefore, think that they need to be considered specifically for the effect of $\mathrm{SO}_{2}$ on asthma.

Response data were also obtained for every day of the 3 year study period. As Mount Isa Base Hospital is the only hospital in the city, and the closest town is $>100 \mathrm{~km}$ away, it seems very unlikely that patients would have presented to another hospital. The response measures of the study were dependent on declarations of asthma, wheeze, or shortness of breath on arrival at the emergency department. It is likely that most people presenting with asthma would declare one of these three entities, but it is also possible that patients presenting with conditions other than asthma may declare wheeze or shortness of breath. The most common conditions in this category would be chronic obstructive airways disease and left ventricular failure. This is a weakness of the study, although it is likely that those with chronic obstructive airways disease would be affected by $\mathrm{SO}_{2}$ in a similar fashion to asthmatic subjects, and may also have coexisting asthma.

A lagged response was not investigated because bronchospasm in response to $\mathrm{SO}_{2}$ is known to be immediate and of short duration, typically 30-60 minutes. ${ }^{157}$

There have been several time series analyses of hospital presentations for asthma relative to pollution by $\mathrm{SO}_{2}$ in air. ${ }^{13-27}$ They have been fairly consistent in showing no positive temporal association. ${ }^{13-22}$ However, they have all investigated diffuse rather than point source pollution, characterised by relatively stable and low concentrations of $\mathrm{SO}_{2}$. Our study has examined the effect of brief peaks of $\mathrm{SO}_{2}$ at much higher concentrations in a city otherwise exposed to very low concentrations. Despite these differences, we also have found no evidence of a positive relation between peak $\mathrm{SO}_{2}$ concentrations and hospital presentations or admissions for asthma, wheeze, or shortness of breath.

It is interesting that brief peaks of $\mathrm{SO}_{2}$ at concentrations known to provoke bronchoconstriction in experimental chamber studies of asthmatic subjects ${ }^{2-6}$ are not associated with increased hospital presentations for asthma, wheeze, or shortness of breath. It is possible that asthmatic people may experience symptoms in response to $\mathrm{SO}_{2}$ peaks which are sufficiently brief and minor that they do not require hospital attendance. Given the short duration of response to $\mathrm{SO}_{2}$ and its reversibility with inhaled $\beta_{2}$ agonists ${ }^{9}$ perhaps this is not surprising.

We conclude that brief exposures to high concentrations of $\mathrm{SO}_{2}$ emanating from point sources at Mount Isa do not cause sufficiently serious symptoms in asthmatic people to require hospital presentation.

1 Nadel JA, Salem H, Tamplin B, et al. Mechanisms of bronchoconstriction during inhalation of sulfur dioxide. $\mathcal{F}$ Appl Physiol 1965;20:164-7.

2 Sheppard D, Wong WS, Uehara CF, et al. Lower threshold and greater bronchomotor responsiveness of asthmatic subjects to sulfur dioxide. Am Rev Respir Dis 1980;122: 873-8.

3 Stacy RW, Seal E, House DE, et al. A survey of effects of gaseous and aerosol pollutants on pulmonary function of normal males. Arch Environ Health 1983;38:104-15.

4 Horstman D, Rodger LJ, Kehrl H, et al. Airway sensitivity of Horstman D, Rodger LJ, Kehrl H, et al. Airway sensitivity of
asthmatics to sulfur dioxide. Toxicol Ind Health 1986;2:28998.

5 Sheppard D, Saisho A, Nadel JA, et al. Exercise increases sulfur dioxide induced bronchoconstriction in asthmatic subjects. Am Rev Respir Dis 1981;123:486-91.

6 Bethel RA, Erle DJ, Epstein J, et al. Effect of exercise rate and route of inhalation on sulfur dioxide induced bronchoconstriction in asthmatic subjects. Am Rev Respir Dis 1983; 128:592-6.

7 Linn WS, Avol EL, Shamoo DA, et al. Effect of metaproterenol sulfate on mild asthmatics response to sulfur dioxide exposure and exercise. Arch Environ Health 1988;43:399406.

8 Koenig JQ, Marshall SG, Horike M, et al. The effects of albuterol on sulfur dioxide induced bronchoconstriction in allergic adolescents. F Allergy Clin Immunol 1987;79:54-8.

9 Bascom R, Bromberg PA, Costa DA, et al. Health effects of Bascom R, Bromberg PA, Costa DA, et al. Health effects of
outdoor air pollution. Am f Respir Crit Care Med 1996;153: 3-50.

10 McCullagh P, Nelder JA. Generalised linear models. London: Chapman and Hall, 1983.

11 Hastie T, Tibshirani R. Generalised additive models. London: Chapman and Hall, 1990.

12 Venables WN, Ripley BD. Modern applied statistics with s plus. New York: Springer Verlag, 1994.

3 Ribon A, Glasser M, Sudhivoraseth N. Bronchial asthma in children and its occurrence in relation to weather and air pollution. Ann Allergy 1972;30:276-81.

14 Rao M, Steiner P, Qazi Q, et al. Relationship of air pollution to attack rate of asthma in children. F Asthma Res 1973;11: 23-6.

15 Goldstein IF, Dulberg EM. Air pollution and asthma: search for a relationship. Fournal of the Air Pollution Control Association 1981;31:370-6.

6 Richards W, Azen SP, Weiss J, et al. Los Angeles air pollution and asthma in children. Ann Allergy 1981;47:348-54.

17 Goldstein IF, Weinstein AL. Air pollution and asthma: effects of exposures to short-term sulfur dioxide peaks. Environ Res 1986;40:332-45. 
18 Chailleux E, Guyon C, Taddei F, et al. Asthma and atmospheric pollution. A study of admissions to hospital in pheric pollution. A study of admissions to

19 Tseng RYM, Li CK, Spinks JA. Particulate air pollution and hospitalization for asthma. Ann Allergy 1992;68:425-32.

hospitalization for asthma. Ann Allergy 1992;68:425-32.
Schwartz J, Slater D, Larson TV, et al. Particulate air polluSchwartz J, Slater D, Larson TV, et al. Particulate air pollu-
tion and hospital emergency room visits for asthma in Seattle. Am Rev Respir Dis 1993;147:826-31.

21 Castellsague J, Sunyer J, Saez M, et al. Short-term association between air pollution and emergency room visits for asthma in Barcelona. Thorax 1995;50:1051-6.

22 Schouten JP, Vonk JM, de Graaf A. Short term effects of air pollution on emergency hospital admissions for respiratory disease: results of the APHEA project in two major cities in The Netherlands. F Epidemiol Community Health 1996, 50(suppl 1):S22-9.
23 Bates DV, Sizto R. Air pollution and hospital admissions in Southern Ontario: the acid summer haze effect. Environ Res 1987;43:317-31.

24 Bates DV, Baker-Anderson M, Sizto R. Asthma attack periodicity: a study of hospital emergency visits in Vancouver. Environ Res 1990;51:51-70.

25 Ponka A. Asthma and low level air pollution in Helsinki. Arch Environ Health 1991;46:262-70.

26 Rossi OVJ, Kinnula VL, Tienari J, et al. Association of severe asthma attacks with weather, pollen, and air pollutants. Thorax 1993;48:244-8.

27 Walters S, Griffiths RK, Ayres JG. Temporal association between hospital admissions for asthma in Birmingham and ambient levels of sulphur dioxide and smoke. Thorax 1994;49:133-40.

\section{Occupational and Environmental Medicine - http://www.occenvmed.com}

Visitors to the world wide web can now access Occupational and Environmental Medicine either through the BMJ Publishing Group's home page (http://www.bmjpg.com) or directly by using its individual URL (http://www.occenvmed.com). There they will find the following:

- Current contents list for the journal

- Contents lists of previous issues

- Members of the editorial board

- Subscribers' information

- Instructions for authors

- Details of reprint services.

A hotlink gives access to:

- BMJ Publishing Group home page

- British Medical Association website

- Online books catalogue

- BMJ Publishing Group books.

The web site is at a preliminary stage and there are plans to develop it into a more sophisticated site. Suggestions from visitors about features they would like to see are welcomed. They can be left via the opening page of the BMJ Publishing Group site or, alternatively, via the journal page, through "about this site". 